\title{
Der normativ-rechtliche und politische Kontext
}

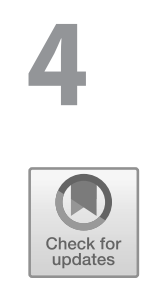

Das LWTG des Landes Rheinland-Pfalz steht im Kontext der „Modernisierung“ der Heimaufsicht seit der Föderalismusreform von 2006. Dabei ordnet sich die vorliegende Reformfragestellung m. E. systematisch ein in den gesamten kohärenten Gestaltwandel der rheinland-pfälzischen Demografiepolitik und ist auch im Kontext der gesamten Pflegepolitikreform ${ }^{142}$ zu verorten. Dabei werden die Entwicklungsprobleme der stationären Langzeitpflege ${ }^{143}$, die medizinische Primärversorgung einbeziehend ${ }^{144}$, und des stationären Wohnens überaus deutlich.

In der Sozialraumorientierung dieser Politik ${ }^{145}$ geht es um eine Differenzierung der Wohnlandschaften im Alter(n) sowie um eine auf Selbstbestimmung und (auch digitale $^{146}$ ) Teilhabe abstellende Transformation der professionellen Formen von Versorgungseinrichtungen im SGB XI und SGB XII im Kontext regionaler Pflegestrukturplanung (die kommunale Daseinsvorsorge ${ }^{147}$ gemäß Art. 28 GG vor dem Hintergrund ${ }^{148}$ der Infrastrukturgewährleistungsaufgabe der eigengesetzlichen Länder gemäß $\$ 9$ SGB XI betonend) und der Generierung lokaler sorgender Gemeinschaften, also $\$ 8$ des SGB XI aufgreifend. Eine nähere Darlegung der normativ-rechtlichen Zusammenhänge ist hier nicht notwendig.

142 Schulz-Nieswandt, 2020c.

143 Schulz-Nieswandt, 2020a.

144 Schulz-Nieswandt, 2020 i.

145 Schulz-Nieswandt, 2017b; 2020e. Ferner: Schulz-Nieswandt, 2018a; 2018d; 2019d; 2019e.

146 Schulz-Nieswandt, 2020g; 2019c; 2020g.

147 Schulz-Nieswandt, $2019 f$.

148 Und vor dem Hintergrund - im Mehr-Ebenen-System der Rechtsregime - der europarechtlichen Regelungen der Dienstleistungen von allgemeinem Interesse. Vgl. auch Wiesner, 2018.

(C) Der/die Autor(en), exklusiv lizenziert durch

Springer Fachmedien Wiesbaden GmbH, ein Teil von Springer Nature 2021

F. Schulz-Nieswandt, Gewährleistungsstaatlichkeit zwischen Wächterfunktion und Innovationsinkubator, Vallendarer Schriften der Pflegewissenschaft 7, https://doi.org/10.1007/978-3-658-32916-7_5 